\section{Chronic anemia masking a primary large B-cell lymphoma of the small intestine, finally diagnosed by double-balloon enteroscopy}
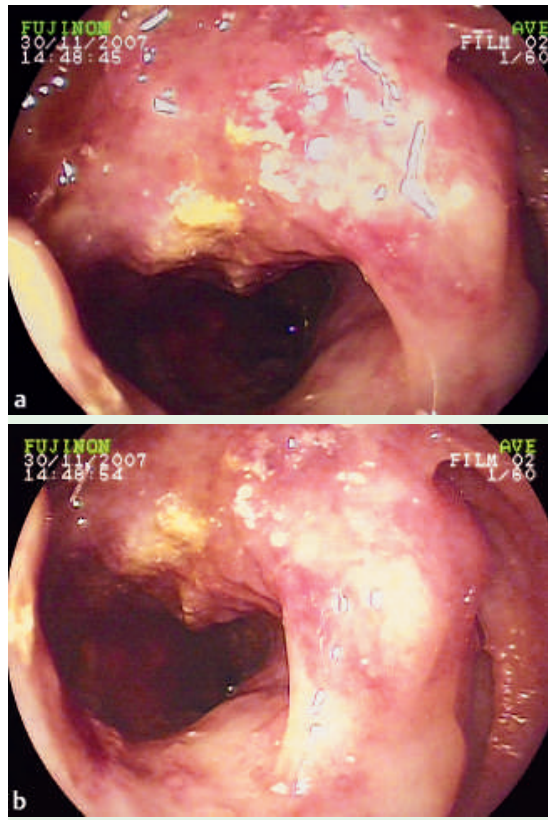

Fig. 1 a, b Endoscopy showing a suspect area approximately $250 \mathrm{~cm}$ distal to the ligament of Treitz.

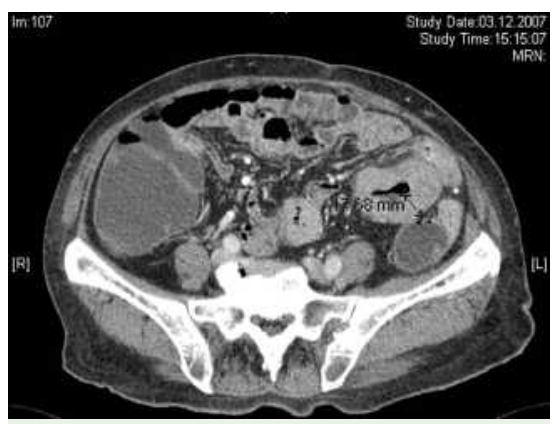

Fig. 2 Contrast-enhanced hydro-CT scan showing thickened wall of the jejunum and enlarged lymph nodes, suggestive of lymphoma infiltration.

A 78-year-old woman was transferred to our hospital with a history of chronic anemia (hemoglobin 80-90 g/L) for several months that was refractory to iron treatment. Repeated gastroscopy and colonoscopy showed no abnormal findings. During the ensuing wireless capsule endoscopy, mucosal changes interpreted as 'possibly ulcerations' located within the distal part of the jejunum were identified as a possible source of bleeding. We performed double-balloon enteroscopy (DBE) to confirm these findings and carry

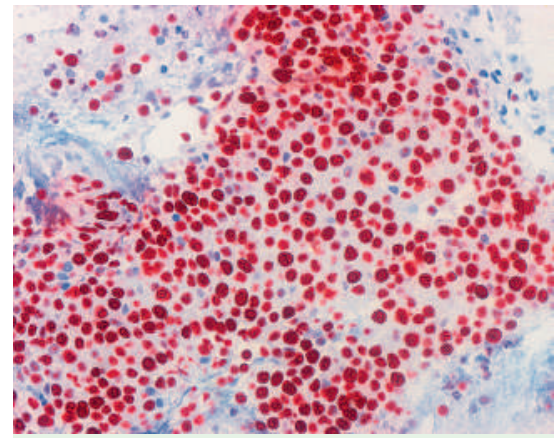

Fig. 3 Histological section of the mucosal area shown in Fig. 1, showing a diffuse large Bcell lymphoma. All proliferating cells are immunohistochemically stained using MiB-1. Original magnification $\times 20$.

out tissue sampling. Approximately $250 \mathrm{~cm}$ distal to the ligament of Treitz we identified a polypoid elevated mucosal lesion of inflamed appearance with erosions and flat ulcerations ( $\bullet$ Fig. 1) During further diagnostic evaluation using hydro-CT, a lymphoma of the small bowel (jejunum) was suggested (๑ Fig. 2). In addition, many nonenlarged mesenteric and retroperitoneal lymph nodes were described. Histological analysis of the biopsies taken during DBE showed an intestinal B-cell lymphoma with diffuse large cells ( Fig. 3). Any thoracic or mediastinal manifestation was excluded by CT scan. Bone marrow histology and cytology demonstrated normal findings with slightly enhanced erythropoiesis and no infiltration by lymphoma cells. Serology showed slight anemia and iron deficiency, as well as enhanced values for CD25 $(6601 \mathrm{U} / \mathrm{mL}$ normal $<900 \mathrm{U} / \mathrm{mL})$, LDH $(350 \mathrm{U} / \mathrm{L}$, nor$\mathrm{mal}<248 \mathrm{U} / \mathrm{L})$ and $\beta$-microglobulin $(4.9 \mathrm{mg} / \mathrm{L}$, normal $<2.5 \mathrm{mg} / \mathrm{L})$. A diagnosis of primary B-cell lymphoma of the small intestine was made.

Small-bowel lymphomas are not typically associated with occult bleeding $[1,2]$. The most commonly described symptoms are weight loss, diarrhea, obstruction, and abdominal pain $[3,4]$. The case presented here supports the idea that capsule endoscopy and DBE may be considered as preferred procedures in evaluating chronic anemia that is suggestive of intestinal lymphoma.

Endoscopy_UCTN_Code_CCL_1AC_2AC

K. Weigand ${ }^{1}$, T. M. Ganten ${ }^{1}$, M. Andrulis ${ }^{2}$, W. Stremmel ${ }^{1}$, P. Sauer ${ }^{1}$, A. Schaible ${ }^{3}$

${ }^{1}$ Department of Gastroenterology and Hepatology, University Hospital Heidelberg, Germany

2 Department of Pathology, University Hospital Heidelberg, Germany 3 Department of General Surgery, University Hospital Heidelberg, Germany

\section{References}

1 Daum S, Ullrich $R$, Heise $W$ et al. Intestinal non-Hodkin's lymphoma: a multicenter prospective clinical study from the German Study Group on Intestinal non-Hodkin's Lymphoma. J Clin Oncol 2003; 21: 2740

2 Hatzaras I, Palesty JA, Abir $F$ et al. Smallbowel tumors: epidemiologic and clinical characteristics of 1260 cases from the Connecticut tumor registry. Arch Surg 2007; 142: 229-235

3 Yin L, Chen CQ Peng CH et al. Primary smallbowel non-Hodgkin's lymphoma: a study of clinical features, pathology, management and prognosis. J Int Med Res 2007; 35: $406-415$

4 Al-Saleem T, Al-Mondhiry H. Immunoproliferative small intestinal disease (IPSID): a model for mature B-cell neoplasms. Blood 2005; 105: 2274-2280

\section{Bibliography}

DOI $10.1055 / \mathrm{s}-2007-995772$

Endoscopy 2008; 40: E149

(c) Georg Thieme Verlag KG Stuttgart · New York . ISSN 0013-726X

\section{Corresponding author}

\section{K. Weigand, MD}

Department of Gastroenterology and Hepatology Medizin IV, University Hospital Heidelberg Im Neuenheimer Feld 410

69120 Heidelberg

Germany

kilian_weigand@med.uni-heidelberg.de 